\title{
ARTIGOS
}

DOSSIÊ TERRITÓRIO, GÊNERO E INTERSECCIONALIDADES

\section{O ATIVISMO DAS MULHERES NEGRAS ESCRAVIZADAS NO BRASIL COLONIAL E PÓS-COLONIAL, NO CONTEXTO DA AMÉRICA LATINA}

\author{
Maria Amoras* \\ Solange Maria Gayoso da Costa \\ Luana Mesquita de Araújo ** \\ *Universidade Federal do Pará, Faculdade de Serviço Social e Programa de Pós-Graduação em Serviço Social, \\ Belém, PA, Brasil \\ ${ }^{*}$ Universidade Federal do Pará, Faculdade de Serviço Social, Belém, PA, Brasil
}

\section{Resumo}

Este artigo é parte de uma pesquisa maior que investiga o protagonismo das mulheres quilombolas na luta pelo território em duas regiões brasileiras: Norte e Sul. Ele apresenta os resultados de uma Revisão Sistemática da Literatura (RSL), artigos, teses e dissertações, que buscou responder à seguinte pergunta: quais as condições de vida e as estratégias de resistência das mulheres negras escravizadas no contexto de colonização da América Latina e, particularmente, do Brasil? Para isso, analisa a produção científica dos últimos cinco anos a respeito das estratégias de organização social e política dessas mulheres nos séculos XVIII e XIX. Os resultados das análises apontam que a "abolição ou anulação" da escravidão não se deu sem os ativismos dessas mulheres, que resistiram de diversas formas nos espaços público e privado, embora tenham permanecido invisibilizadas pelas intersecções de gênero, raça e classe e suas inúmeras tessituras nos sistemas de dominação.

Palavras-chave

Feminismo Negro; Mulheres Negras; Território Tradicional; Diáspora; América Latina. 


\title{
ENSLAVED BLACK WOMEN'S ACTIVISM IN COLONIAL AND POSTCOLONIAL BRAZIL, IN THE LATIN AMERICA CONTEXT
}

\author{
Maria Amoras* \\ Solange Maria Gayoso da Costa* \\ Luana Mesquita de Araújo ** \\ *Universidade Federal do Pará, Faculdade de Serviço Social e Programa de Pós-Graduação em Serviço Social, \\ Belém, PA, Brazil \\ ${ }^{*}$ Universidade Federal do Pará, Faculdade de Serviço Social, Belém, PA, Brazil
}

\begin{abstract}
This discussion is part of a larger research on the protagonism of Quilombola women in the struggle for territory in two Brazilian regions: North and South. It presents the results of a Systematic Literature Review that sought to answer: what were the living conditions and resistance strategies of enslaved Black women during the colonial period in Latin America, particularly in Brazil? It analyzes the scientific production, published in the last five years, that shows these women's strategies of social and political organization in the 18th and 19th centuries. The results indicate that the "abolition or suppression" of slavery could not have happened without the activism of these women, who resisted in different ways in the public and private spaces, although they remained invisible due to the intersections of gender, race and class and their contextures in the domination systems.

Keywords

Black Feminism; Black Women; Traditional Territory; Diaspora; Latin America.
\end{abstract}




\title{
O ATIVISMO DAS MULHERES NEGRAS ESCRAVIZADAS NO BRASIL COLONIAL E PÓS-COLONIAL, NO CONTEXTO DA AMÉRICA LATINA
}

\author{
Maria Amoras \\ Solange Maria Gayoso da Costa \\ Luana Mesquita de Araújo
}

\section{Palavras iniciais}

Este artigo apresenta os resultados de uma Revisão Sistemática da Literatura (RSL), que, orientada por um protocolo de pesquisa, buscou responder à seguinte pergunta: quais as condições de vida e as estratégias de resistências das mulheres negras africanas escravizadas no contexto da colonização na América Latina e, particularmente, no Brasil? Para isso, ele investiga a produção científica que trata das estratégias de organização social e política de mulheres escravizadas, crioulas e forras nos séculos XVIII e XIX, em contextos coloniais e pós-coloniais. A análise intenta compreender o ativismo dessas mulheres na sobrevivência e manutenção de seus grupos.

A discussão subsidia uma pesquisa maior que objetiva investigar o protagonismo das mulheres quilombolas na luta pelo território tradicionalmente ocupado em duas regiões brasileiras: norte da Amazônia e Sul. O estudo parte do entendimento teórico de que existe uma relação dialética que une opressão e ativismo, como compreende Patrícia Collins (2019) em suas reflexões e análises sobre o não reconhecimento das lutas históricas das mulheres contra a sociedade racista. Para a autora, as mulheres negras, mesmo no contexto da escravidão, nunca foram pacíficas, como indicam documentos historiográficos. Pelo contrário, sempre resistiram às opressões, lutaram e continuam lutando de diversas formas para sobreviver, ainda que seus enfrentamentos não sejam vistos como ativismos e ações políticas contra o Estado.

Os feminismos negros têm se expandido nos tempos atuais na América Latina, como no caso do Brasil, país de maioria negra e último a abolir a escravidão. 
As lutas das mulheres quilombolas começam a ganhar visibilidade em suas pautas, tal como em tempos pretéritos, nas Américas. Versam sobre o direito à sobrevivência e à garantia de territórios tradicionalmente ocupados, os quais têm a matrilinearidade como marcador relevante da ancestralidade. Neles, as mulheres pluralizam perspectivas na política de gestão da terra, construindo relações estreitas entre trabalho, educação dos filhos, rede de parentesco e religiosidade. Trata-se, assim, de espaços com lógicas e dinâmicas combinadas e negociadas na constituição relacional com os espaços públicos, privados, coletivos e sagrados.

Para Patrícia Collins (2019), a sobrevivência, ao lado de seus filhos, sempre foi a maior bandeira de luta das mulheres negras, representando o alicerce de seus ativismos. Assim, só foi possível às afro-americanas se manterem na diáspora pela resistência às opressões racial e de classe com vistas a garantir a sobrevivência do grupo. Todavia, como dito anteriormente, é um ativismo invisibilizado, pois determinadas perspectivas do movimento social que não interseccionam gênero, raça e classe costumam ignorar que a luta pela sobrevivência do grupo é tão importante quanto os enfrentamentos com o poder institucional.

O saber ancestral mobilizado por essas mulheres para construir estratégias de resistência e de organização política institucional tampouco é reconhecido como poder e força de transformação social em muitas instituições acadêmicas. Contudo, muitas delas, as "forasteiras de dentro" (COLLINS, 2016), ao longo da história, passaram a pertencer a algum dos vários grupos de intelectuais marginais, cujos pontos de vista formaram as distintas vertentes do feminismo negro e dos feminismos na América Latina. O pensamento crítico e engajado delas muito enriquece (e enriqueceram) o discurso sociológico contemporâneo no Brasil, como Maria Firmina dos Reis, Carolina de Jesus, Lélia Gonzales, Conceição Evaristo, Sueli Carneiro, Jurema Werneck, Djamila Ribeiro, Carla Akotirene, entre outras.

O trabalho dessas intelectuais está voltado à reflexão sobre a relação dialética entre opressão e resistência na vida das mulheres negras escravizadas. Orientadas por essa episteme, o esforço das autoras deste texto não visou a evidenciar a espoliação do corpo negro de forma essencializada, mas, sim, a atentar-se às peculiaridades da resistência desses corpos ao longo de séculos ao enfrentar os requintes mais cruéis de opressão. A intenção maior foi mostrar o modo como essas mulheres foram oprimidas e enfrentaram o sistema escravocrata nos espaços público e privado.

As reflexões aqui realizadas resultam de análises de artigos, teses e dissertações conforme parâmetros da RSL. O recorte temporal utilizado no levantamento seguiu o critério de produções acadêmicas dos últimos cinco anos. Outros critérios de seleção também foram considerados, como acesso gratuito, ausência de duplicidade dos trabalhos e idioma das publicações, que deveriam estar em português ou espanhol. No que diz respeito aos locais de busca, seguindo o protocolo da 
pesquisa, foram coletados materiais nas bases de dados das plataformas SciELO, Capes e Google Acadêmico. O material levantado reuniu 55 documentos (49 artigos, 5 teses de doutorado e 1 dissertação de mestrado), produzidos nos campos da história, da sociologia e da antropologia.

Por fim, vale pontuar que a referência às autoras citadas no texto é feita pelo primeiro nome, seguido do sobrenome. A proposta de nomeá-las desse modo parte da iniciativa de abordar o lugar das mulheres na historiografia, pois o uso apenas do sobrenome remete à naturalização da identificação dos homens na produção intelectual. Aqui se defende a visibilidade e o reconhecimento das "forasteiras de dentro", como discute Patrícia Collins (2016), como autoras e produtoras de conhecimento científico. Com elas, foi possível identificar ideias de um ser-viver anticolonial no feminismo negro, ideias que forçam os pensamentos sociológicos e antropológicos contemporâneos a encontrar novas formas de ver a realidade vivenciada.

2. Trajetórias de mulheres negras escravizadas na América Latina: repensando a diáspora africana

A imersão na temática da diáspora forçosa e atroz da população africana escravizada para as Américas possibilitou observar que essa dívida histórica, conforme discute Sônia dos Santos (2015), alcançou um número superior a cinco milhões de pessoas escravizadas, com índices mais elevados entre os séculos XVIII e XIX. Junto disso, os estudos permitiram compreender que as Américas também apresentam na atualidade uma face real e grotesca do que foi o período colonial, sobretudo porque são povoadas por civilizações imersas nos traumas e anseios da ancestralidade cerceados pela subalternização.

Para iniciar, é importante ressaltar que o contexto de colonização nas Américas apresenta arquétipos distintos, nos quais se destacam as diferentes formas como homens e mulheres escravizados foram oprimidos. No que se refere às condições de escravizados no período colonial, mulheres negras eram alvo de requintes cruéis, a saber: jornadas excessivas de trabalho, objetificação, recorrentes violações dos seus corpos, impedimento da maternidade, dos afetos, da religiosidade. Muitas delas, "para responder às duras urgências do novo presente, decidiram não ter filhos escravos. Assim, comprometeram seus órgãos sexuais aplicando plantas nocivas” (CABRERA, 2017, p. 121).

Reafirmando tais condições dos escravizados, Olga Cabrera (2017) aponta como foi o processo de subalternização de povos africanos na América Latina e quanto esse processo se assemelha em diversos países e ex-colônias. Em Cuba, em 1531, a base da economia começa a se afirmar com a produção e estocagem de tabaco, sendo esta uma atividade cotidiana das mulheres e dos homens negros escravizados. Todavia, as mulheres eram as mais exploradas, porque, ao final da jornada 
de trabalho na lavoura, tinham de alimentar no seio os filhos das mulheres brancas, em vez de seus próprios filhos, quando já eram também mães.

Observando os contextos históricos analisados por Olga Cabrera e a questão da diáspora em Cuba, Beatriz Esteve (2014) realiza um estudo temporal acerca do comércio de escravizados, no período de 1790 a 1840, de uma perspectiva de gênero. O foco principal da autora é descobrir quais foram as motivações sociais, econômicas e políticas que levaram à comercialização de mulheres negras escravizadas na nação cubana. A princípio, ela aponta a ausência de dados e a imprecisão no quantitativo de mulheres pretas traficadas para o país. Diante disso, sua principal fonte de pesquisa foi a Trans-Atlantic Slave Trade Database (TSTD)', que também apresenta certa ausência de dados sobre o quantitativo de mulheres escravizadas. Dessa maneira, é possível questionar: os colonizadores, aos menos, consideravam a existência de mulheres em meio ao tráfico e captura desses sujeitos? Os relatos presentes no artigo de Beatriz Esteve (2014) revelam que a ação violenta do colonizador sobre os povos africanos encerrava mulheres, homens e crianças em uma só classificação: pretos primitivos, os escravos.

Um ponto instigante na comercialização de escravos em Cuba, de acordo com a autora, remete à existência de uma intensa mão de obra escravizada masculina nas senzalas do país, com pouca presença da força de trabalho feminina. E isso se deveu ao fato de Cuba apresentar, no período de 1790 a 1840, atividades manufatureiras ligadas à exploração e comercialização da cana de açúcar; do ponto de vista dos donos de engenhos, era mais vantajoso ter nas feitorias homens escravizados, pois se considerava que o homem possuía a força que os trabalhos nas lavouras exigiam. As mulheres escravizadas eram compradas para a manutenção da força de trabalho masculina, ou seja, para reprodução de homens. Elas eram mais caras que os homens escravizados. Como analisa a autora:

Según diversos estudios y documentos del archivo, las mujeres del campo se ocupaban básicamente de tareas domésticas, pero era un número muy reducido todavía. Por este motivo, no llegaban más mujeres a Cuba como esclavas, dado que eran consideradas solo para "reproducir mano de obra", aunque salían más caras que comprar directamente varones en edad de producir, a diferencia de lo que había opinado Arango en un principio (ESTEVE, 2014, p. 115-116).

\footnotetext{
1. Base de dados aperfeiçoada por Davis Eltis para estimar o tráfico atlântico de escravizados. A TSTD conseguiu reunir até o presente 36 mil viagens, que registram mais de 12 milhões de pessoas traficadas forçadamente da África para as Américas, com mais de um milhão de mortes ocorridas entre a viagem e a chegada. Ver https://www.slavevoyages.org/. Acesso em: 9 set. 2021.
} 
O aumento de mulheres escravizadas em Cuba partiu da necessidade, com a expansão das cidades, de se ter mais mão de obra feminina. A partir de 1807, fazendeiros, com receio de não conseguirem mais traficar, optaram por comercializar mais mulheres para o trabalho doméstico na cidade: "Las labores de las esclavas, que podemos encontrar en los periódicos de la época, eran muy diversas: cocineras, costureras, planchadoras, lavanderas, etc." (ESTEVE, 2014, p. 120). De todo modo, as atividades mais corriqueiras - e de extrema relevância nesse contexto - eram as das parteiras e amas de leite, em função dos intensos projetos de aumento populacional de brancos no país.

Como conclusão, Beatriz Esteve (2014) aponta que a sociedade escravista, em Cuba oitocentista, apresentou dois momentos importantes: o primeiro deles refletia a necessidade de uma mão de obra escravizada masculina, em função das atividades econômicas no campo, as quais eram ligadas à venda e comercialização de cana-de-açúcar; o segundo se ligou ao desenvolvimento das cidades e à abolição em alguns países, o que determinou a maior presença de mulheres escravizadas e recém-libertas, pois as atividades que a população escravizada desenvolvia visavam à obtenção de maior lucro.

No que tange às condições de vida das mulheres negras na região caribenha, Lorena Telles (2018) descreve como se davam as relações escravistas na América Central, precisamente, na Jamaica. A autora comenta que, em parte, as atividades desenvolvidas pelas mulheres negras escravizadas eram controladas pelos senhores de escravos e governo colonial. Ademais, os médicos da região procuravam formas de controlar os corpos delas, a fim de não comprometer as atividades que desenvolviam nas zonas açucareiras. Segundo Lorena Telles (2018, p. 26):

Pesquisadores revelaram que, nas grandes propriedades jamaicanas, marcadas por grande população de escravizados e pelo absenteísmo dos senhores europeus, as violências sexuais praticadas por feitores e administradores contra as africanas e crioulas escravizadas adquiriram contornos de uma política de dominação, envolvendo rituais de humilhação pública dirigidas a elas e às comunidades escravas, constantemente alimentadas pelo tráfico.

No período oitocentista caribenho, predominava a preconceituosa denominação de mulheres “jezebel”, como estudou Lorena Telles (2018). Tal termo, segundo a autora, remetia à "figura que reunia os atributos da jovem escrava sedutora e de sexualidade exacerbada, em constante procura por contatos sexuais e pelos supostos privilégios daí decorrentes” (TELLES, 2018, p. 27). Essa autora ressalta, ainda, que os imaginários grotescos acerca dos corpos das mulheres negras naturalizavam os atos violentos que elas sofriam, como tortura e estupro. 
Além de lidar com essas violências, elas eram obrigadas a engravidar e a criar filhos frutos de violência sexual. Mesmo no pós-abolição, a violência sexual não cessou, e elas tiveram de continuar engravidando-se e criando esses filhos.

Nas ilhas caribenhas, as mulheres grávidas escravizadas trabalhavam de forma intensa nas lavouras, eram proibidas de aleitamento e recebiam, ainda, outras restrições ligadas aos cuidados de suas crianças. Um dado importante: conforme pesquisas sobre mulheres escravizadas em outros países e ex-colônias, as "cativas" que enfrentavam os trabalhos forçosos nas lavouras de exportação de cana-de açúcar apresentavam baixos índices de fertilidade (TELLES, 2018). Desse modo, a autora aponta que as mulheres negras escravizadas tiveram um intenso movimento com a produção agrícola, bem como com insumos da indústria açucareira.

Como assinalado antes, as mulheres negras escravizadas nas ilhas caribenhas tinham de suportar as consequências traumáticas da maternidade, lidando, mesmo adoecidas emocionalmente, com filhos provenientes de estupros. Porém, elas não se calaram perante as crueldades infligidas sobre seus corpos. Na Jamaica e em Barbados, como afirma Lorena Telles (2018, p. 32), "ceifar a vida de bebês e crianças foram respostas centrais aos papéis das mulheres na resistência à escravidão, que teriam contribuído para a falência da reprodução no contexto caribenho".

Diante disso, importa destacar que as experiências de escravização na América Latina e nas ilhas caribenhas não foram contestadas apenas pela insurgência dos homens, como é comum aparecer até mesmo na historiografia crítica. Paula Melo (2015) classifica essas insurgências de homens e mulheres como importantes ações de formação de núcleos de heranças afro-diaspóricas latino-americanas e caribenhas:

[...] foram diversas as insurgências que marcaram a organização de mulheres e homens negros, os quais prevaleceram sobre o nome de quilombos, mocambeiros e mocambos, no Brasil; Palenques, na Colômbia, Equador, Cuba, México, Panamá e Peru; Cumbes na Venezuela; Maroons no Haiti, Jamaica e demais ilhas do Caribe francês; Batey, na República Dominicana. (MELO, 2015, p. 38)

Paula Melo (2015) também reúne em sua tese um arcabouço histórico social acerca dos povos escravizados na Colômbia e no Equador. A partir de dados históricos valiosos, ela aborda as dinâmicas territoriais e as organizações políticas que prevaleceram do período colonial à contemporaneidade. Assim, na realidade histórica e social colombiana, as concepções de raça obedeceram às classificações mais diversas: "negro/a”, "índio/a”, "mulato/a”, "zambo/a” e "zambahiago”, sendo que esta última se refere a uma categoria étnico-racial resultante da mescla negro-indígena (MELO, 2015). 
A autora ressalta que, no período colonial colombiano, era recorrente o predomínio de grupos espanhóis que dominavam os indígenas para que exercessem atividades nos minérios. Com base nos dados da historiografia latino-americana, Paula Melo (2015) descreve a presença de atividades ligadas à mineração no período colonial colombiano, demarcando a predominância de trabalhos realizados em minas de ouro das Províncias do Sul colombiano (Popayán, hoje Barbacoas) e em Tumaco. A partir de 1640, ocorreu a transição da mão de obra indígena para a negra. Essa mão de obra concentrou-se nas “ocupações” em esteiros, praias, diques, várzeas, braços e boqueirões dos rios, sendo uma marca do período colonial colombiano.

De acordo com a autora, após a abolição na Colômbia, parte das mulheres negras e dos homens libertos migrou para a costa do país; como consequência, formaram pequenas comunidades, onde desenvolviam atividades como pesqueiros, marisqueiros, pescadores e até agricultores (essas ocupações reverberam ainda hoje). Outro traço marcante do período pós-abolição colombiano, conforme a pesquisa da autora, era a presença de castas, usadas para representar e destacar aqueles que não eram brancos: “A 'casta' foi utilizada posteriormente, no século XVIII, para demarcar a posição socioeconômica que correspondia ao indivíduo” (MELO, 2015, p. 69).

Outro aspecto do contexto de escravização e pós-abolição em território colombiano remete ao fato de que escravizadas domésticas eram alvos de diversos requintes de violência pelas senhoras de escravos na região de Cartagena. Esses atos reforçavam a ideia de que "a violência perpetrada contra mulheres negras escravizadas resultava não apenas do antagonismo homem-mulher, mas também das contradições de classe e exploração econômica” (MELO, 2015, p. 51).

Ainda referente ao processo de subjugação de corpos de mulheres negras em regiões colombianas, é preciso indicar que a busca por alforria se configurava de diferentes formas. Paula Melo (2015) indica que o "cimarronismo" e o "zapaco" foram estratégias usais para mulheres negras e homens negros. A primeira delas remete aos escravizados que fugiam dos domínios de "seus senhores", indo para montanhas ou Palenques (espécie de quilombos). Já a segunda trata dos negros e negras que conseguiam escapar dos feitores, mas continuavam a viver nos arredores das cidades. Grande parte das mulheres negras se articulava e resistia às opressões da escravidão, seja pela negociação de cartas de liberdade por serviços prestados, seja pela "compra direta do escravo a seu amo, amizade ou paternalismo e/ ou relações diretas amo-filho, amo-esposa, ou abolição total” (MELO, 2015, p. 53).

Em relação às formas de resistência recorrentes na costa pacífica do Equador, merece destaque o surgimento dos Palenques, grupos aquilombados. 
A região do Equador ficou conhecida por ter os primeiros Palenques formados com a participação de mulheres e homens negros e indígenas como forma de resistência à colonização. Foram identificados como grupos que ocupavam zonas inóspitas, sendo, para eles, uma forma de subverter e resistir à ordem escravista. De acordo com Paula Melo (2015), os Palenques elaboraram diversas estratégias militares de coletivização para viver em território sob domínio dos escravocratas.

Outra característica da colonização no Equador foi existência de um quantitativo de homens negros superior ao de mulheres negras. Ademais, saliente-se a prática da poliginia, usada como uma estratégia de organização do grupo, e dos casamentos interétnicos entre homens negros e mulheres indígenas. Assim, “o exercício de ampla poliginia desde a chegada dos náufragos em Esmeraldas, em 1553, envolvendo, majoritariamente, homens negros e mulheres indígenas, que resultou em elevadas taxas de natalidade" (MELO, 2015, p. 44). Um ponto destacado pela autora - e que deve ser observado aqui - se trata da agência das mulheres nas uniões matrimoniais poligínicas, as quais denotavam uma importante estratégia de sobrevivência diante das atrocidades das investidas dos colonizadores espanhóis. A autora ainda reitera a resistência dessas mulheres na articulação das formas de poliginia:

A família extendida foi um mecanismo de resistência à escravidão,
por um lado, e construção da liberdade, por outro. Em geral, nas qua-
drilhas, estabeleciam-se relações sexuais flexíveis, das quais podiam
participar a maior parte dos homens desse grupo social alternada-
mente com o mínimo de mulheres existentes. A família extensa, en-
gendrada pela sucessão de matrimônios de um mesmo ego genitor,
fez com que os filhos se identificassem com a cabeça da família, de-
nominada gran madre. Assim constituiu-se uma tendência à matrili-
nearidade e matrilocalidade em uma sociedade com patrilinearida-
de legal. (MELO, 2015, p. 48)

Foi desse modo que as mulheres negras passaram a ser reconhecidas como importantes ancestrais nessas organizações familiares, denominadas de quadrilhas. As quadrilhas configuravam-se como

grupos de parentes consanguíneos que remonta[v]am sua linhagem por via materna ou paterna, até um antepassado homem ou mulher fundador da descendência. [Eram] regidos por princípios de solidariedade, cooperação e respeito, marcados pela presença constante da consanguinidade e de regras exogâmicas de conjugalidade. O pertencimento a um tronco confer[ia] direitos de residência, de trabalho e herança sobre as terras de mineração e de cultivos agrícolas. (MELO, 2015, p. 129) 
Podemos dizer, então, que as quadrilhas funcionavam no Equador como estratégias de insurgências feminina no pós-abolição. Elas denotavam a perspectiva de novos arranjos familiares como forma de organização social em contexto afro-diaspórico, com o objetivo de reconstruir um território afro-pacífico, nos termos da autora.

Por sua vez, para o processo de colonização do território argentino, Carvalho (2019) destaca a presença do trabalho forçoso de escravizados no abastecimento de atividades agrícolas ligadas às lavouras de milho, trigo, frutas e outros mantimentos primários, bem como em práticas comerciais que instituíam um mercado comum no período colonial latino-americano. Outras regiões invadidas por hispânicos, como a cidade de Potosí, no alto Peru (hoje Bolívia), subjugavam corpos de mulheres negras e homens negros em atividades minerárias. Os invasores almejavam o Vale da Prata e mercados para gados, trocas de couro e vendas de gorduras.

Um ponto crucial indicado pelo autor se concerne à perspectiva de que os contingentes de mulheres negras traficadas na Argentina, além de sobreviverem às jornadas dolorosas no Atlântico negro, ainda tinham de "fazer o percurso até as chamadas 'províncias do Norte', onde seriam vendidas para a região mineradora de Potosí ou lá permaneceriam como trabalhadoras na produção de gado e/ou alimentos” (CARVALHO, 2019, p. 53).

A colonização na Argentina, segundo Carvalho (2019), deu-se pelo processo de escravização nos primeiros centros urbanos, onde mulheres negras e homens negros desempenhavam atividades no âmbito doméstico ou como escravos de ganho:

Em Buenos Aires, escravos e escravas eram utilizados, seja na economia urbana como servidores domésticos, artesãos e operários de pequenas oficinas, seja na economia rural que abastecia os mercados urbanos, principalmente na produção de couros. (CARVALHO, 2019, p. 22)

Assim como no território argentino, a exploração de escravizados na Colônia do Sacramento (povoado uruguaio) serviu para sustentar as disputas territoriais entre colonizadores portugueses e espanhóis, além de ter sido, sobretudo, um setor temporário de intensos contrabandos dos povos africanos. Kühn (2017) explicita que no mercado de escravizados em regiões do Uruguai predominou a comercialização com vistas à reposição de mão de obra escravizada. Não obstante, "uma parte desses escravos tinha ocupações na própria Colônia, seja como domésticos e artesãos, seja ainda como trabalhadores no porto e marinheiros” (KÜHN, 2017, p. 4). 


\section{As mulheres negras na ordem escravista brasileira}

O Brasil foi um dos últimos países a aderir à abolição da escravatura. Claudia Miranda e Carla Silva (2019) apontam que as lutas abolicionistas ocorreram de forma gradual e que se manteve a exploração de mão de obra escravizada muitos anos. Aliás, a estrutura racista do projeto escravocrata permaneceu no pós-abolição, reproduzindo estigmas, preconceitos, discriminações e exclusões que sustentam a marginalização dessa população no tempo presente. As mulheres negras africanas também protagonizaram táticas de resistência para construir a emancipação em terras brasileiras. A respeito das realidades delas, as duas estudiosas reiteram:

[...] em 1857 as mulheres negras ainda eram escravizadas. Estavam nas lavouras, na casa grande, nas senzalas, nas ruas, produzindo sem descanso devido, sem benefícios, sem alimentação adequada. As mulheres negras escravizadas - ou mesmo as libertas - resistiam um dia de cada vez. [...] organizavam e lutavam de diferentes formas, por seus direitos, como escravizadas. E mesmo quando não tinham o reconhecimento e status de cidadãs, imprimiram estratégias exemplares de reinvenção de si. Participaram de movimentos que nasceram da sobrevivência dos tumbeiros, ou da própria terra de Vera Cruz. (MIRANDA; SILVA, 2019, p. 103)

Ivana Lima (2018) também aborda as experiências femininas negras no comércio, mas com uma nova ordem de comunicação, a escrita ${ }^{2}$. Um ponto específico sinalizado pela autora diz respeito à situação de mulheres negras africanas no contexto do pós-abolição no Brasil. Ela mostra que as mulheres que iniciaram suas primeiras atividades em pequenos comércios eram aquelas que traziam práticas ancestrais das suas tradições culturais com as experiências econômicas entre países que correspondiam à antiga Costa da Mina, no continente africano.

Nos estudos de Marilia Ariza (2018), também foram encontradas perspectivas de resistência no processo de alforriamento de mulheres negras no mesmo contexto de pós-abolição. Ela constrói um recorte histórico das lutas de mulheres negras pela alforria de seus filhos, descrevendo suas trajetórias para conseguir a promessa de "liberdade". Muitos senhores e senhoras cobravam pelas cartas de alforria, isto é, a troca acontecia por meio de extensas jornadas de trabalho. Assim, a pseudoliberdade era obtida pela continuidade do trabalho intenso em diversas atividades que lhes possibilitavam a economia de míseros pecúlios. Como sublinha a autora:

2. A autora realiza reflexões contundentes acerca de como africanas escravizadas resistiram à escravidão por meio de estratégias de comunicação para enfrentar o sistema opressor. Assim, busca sistematizar a dimensão linguística da escravidão de africanos no Brasil, tendo como foco o protagonismo feminino negro. 
[...] mobilizava esforços variados formando nova poupança, arranjando-se múltiplos empréstimos e uma fiadora e comprometendose, ao fim e ao cabo, com uma dívida nada módica de um conto e quinhentos mil réis, a serem pagos em um ano. (ARIZA, 2018, p. 152) ${ }^{3}$

As recém-libertas passavam a enfrentar todos os obstáculos possíveis em decorrência dos ínfimos pagamentos que recebiam pelos serviços domésticos prestados nas cidades, que mal garantiam os custos com alimentação e manutenção de suas famílias e outros parentes. A análise crítica da historiografia nacional realizada por Marília Ariza (2018) possibilita observar que essa mulher, ao se submeter ao trabalho árduo para conquistar a alforria, tinha em mente o projeto de emancipação feminino compartilhado com outras mulheres e da própria família. É compreensível, assim, que a defesa da autonomia de seus corpos e de seus filhos estivesse no projeto de libertação defendido pelas mulheres. Isso revela ou reforça o dado da prevalência de se ter mais mulheres libertas em contexto pós-colonial do que homens. Em consonância com esses apontamentos, a autora conclui:

De fato, diversos estudos sobre alforria têm, há algum tempo, indicado a prevalência de mulheres entre os cativos beneficiados por manumissões, fossem elas conquistadas em ajustes incondicionais, que cumpriam o papel simbólico de atestar a benevolência senhorial, ou condicionais, associadas à prestação de serviços ou a indenizações monetizadas. Não obstante, certo olhar historiográfico que identifica a manumissão de mulheres escravizadas e seus filhos a arranjos de natureza íntimo-sexual entre cativas e senhores, reconhecidamente legatário de narrativas sobre a lubricidade da mulher negra e da mestiçagem brasileira, mostra-se ativo ainda nos dias de hoje, desdenhando a importância da capacidade de trabalho e de improviso de modos de vida entre cativas e libertas. (ARIZA, 2018, p. 153)

Com base nisso, pode-se afirmar que as diversas possibilidades de articulações dessas mulheres em busca de alforriamento compreendiam uma postura política de extrema complexidade e relevância, uma vez que se constituíam em táticas de sobrevivência com possibilidade de libertar os filhos do ciclo da escravidão: “iniciá-los pela manumissão materna era uma opção estratégica que levava em consideração os amplos esforços necessários para a aquisição ou conquista judicial de diversas alforrias” (ARIZA, 2018, p.153). Com efeito, as mulheres negras criaram muitas estratégias para subverter a ordem do sistema, porque a sociedade escravista brasileira, em período pós-colonial, continuou sendo uma ameaça às suas vidas, levando-as

3. Ao abordar essas perspectivas, a autora utiliza como fontes de dados os registros oficiais e os relatos sobre memórias de mulheres negras que viveram à margem da classe senhorial paulistana. 
a buscar arranjos de serviços pelos arredores das cidades para alcançar melhores condições de sobrevivência. Acerca disso, a autora assinala que

[a]lgumas delas, a exemplo do que ocorria às mulheres empobrecidas chefes de família de forma geral, procuravam na formação de alianças com antigos senhores ou novos patrões uma medida de acomodação que contemplasse a expectativa de preservar seus laços com os filhos e mantê-los, tanto quanto possível, próximos de seus cuidados, ainda que dentro de estreitas margens de autonomia. (ARIZA, 2018, p. 156)

Além da extirpação de suas maternidades, essas mulheres tiveram de lidar com outras violências, como a venda de seus parceiros e o impedimento de casamentos (permitidos somente quando gerassem lucros às sociedades senhoriais). Nesse aspecto, Maísa Cunha (2017), em conformidade com as discussões de Marília Ariza (2018), explicita como se estruturavam as formas de casamentos mistos (entre escravizados e libertos) no contexto pós-abolição, enfatizando que, mesmo durante o período de alforrias, casamentos mistos eram inicialmente proibidos, sendo controlados pelos senhores no intuito de manter o sistema escravista.

Uma observação fundamental identificada nas leituras dos materiais levantados para este estudo sinaliza para o fato de que, mesmo após a abolição dos regimes escravagistas e perda maciça de mão de obra escravizada, a sociedade senhorial da época e os regimentos do período procuraram outras formas de dominação e espoliação, perfazendo, portanto, uma forma de recuperar a força de trabalho alforriada. Ariza (2018) revela que as mulheres forras e recém-libertas sofreram com títulos depreciativos no que tange a seus papéis familiares e, sobretudo, atributos de maternidade, visualizados sempre como "símbolo definitivo das 'mães impróprias' e incapazes de bem educar os filhos, futuro da nação” (ARIZA, 2018, p. 165).

Em consonância com essas considerações, Virginia Barreto (2019) descreve e analisa, a partir de dados oficiais da sociedade senhorial baiana, a trajetória de Maria da Conceição, mulher negra escravizada, conhecida, naquele contexto, por reivindicar a sua liberdade e lutar contra seu aprisionamento injusto. As narrativas presentes no processo jurídico de Maria Conceição dialogam com as explanações de Marília Ariza (2018) ao ratificar que essas mulheres almejavam não apenas emancipações individuais, mas também as de seus familiares. Para complementar, acionando as reivindicações da escravizada Maria Jesuína, Virginia Barreto (2019, p. 103) pontua que "a ação proposta por ela não requeria apenas a sua liberdade, mas, igualmente, a de suas duas filhas e seus sete netos, todos nascidos na escravidão, entre os anos de 1830 e 1875 ”. 
Essas mulheres desempenhavam diversas funções na sociedade escravista baiana. Entre as ocupações mais recorrentes e com condições mais favoráveis, estavam as "escravas de ganho". Como explica Barreto (2019, p. 105):

Com autorização de seus senhores, as escravizadas circulavam pelas povoações e vilas da região comprando e vendendo mercadorias, habitavam casas ou quartinhos de aluguel, e estabeleciam seus horários de trabalho. Ainda que tivessem de prestar conta de suas atividades, era, sem dúvida, uma vida mais 'livre' do que aquela vivenciada por suas companheiras de condição alocadas nas propriedades rurais da região e submetidas à rotina rígida das lavouras.

Cumpre enfatizar, em diálogo com as informações acima, que o conceito de "mulheres forras" se refere às escravas de ganho, as quais utilizavam e poupavam os rendimentos em prol da conquista das alforrias - fato que tornou essas mulheres bastante conhecidas no Rio de Janeiro e em outras áreas da região Sudeste. Considerando o contexto urbano fluminense, Lorena Telles (2019, p. 54) frisa que, na primeira metade do século, com sua economia monetarizada, foram abertas "maiores oportunidades para a negociação da compra da liberdade com seus senhores, o que proporcionou uma importante população de forras na cidade”.

A partir desses relatos, é possível compreender por que as mulheres negras escravizadas buscavam também sobreviver por meio de diferentes ocupações. Mas, entre as atividades mais procuradas, como dito antes, estavam as tarefas das "escravas de ganho", que, segundo a autora, tinham certa autonomia, já que podiam circular pelas vias públicas e retornar ao cativeiro apenas para a prestação de contas das atividades executadas durante a semana: "Além da flexibilidade dos horários de trabalho, podia[m] administrar seus ganhos, construir espaços afetivos e, principalmente, deslocar-se por entre as vilas, freguesias e pequenas povoações rurais do sul do Recôncavo Baiano” (BARRETO, 2019, p. 105-106).

Mesmo que certas atividades estivessem entre as mais ansiadas pelas escravizadas, isso não significa que eram menos violentas ou de menor carga de trabalho. Virginia Barreto (2019) apresenta as atividades de outra mulher negra e "escrava de ganho": Antônia Francisca. Essa mulher, que teve rotinas de trabalho extensas e pesadas, vendia pelos mercados e arredores de vilarejos no Recôncavo baiano em busca de lucros para os senhores. Essa era a rotina de trabalho de tantas outras "escravas de ganho", que sempre percorriam grandes distâncias, atravessavam rios, circundavam matas fechadas, arriscando-se de diversas formas em função das vendas para aumentar os lucros dos senhores.

Virginia Barreto (2019) também identifica os laços de coletividade e solidariedade entre mulheres negras recém-libertas, pois, embora tenham se enveredado 
em espaço e tempo distintos, suas trajetórias se entrecruzavam: "Durante o tempo em que ali viveu, Antônia construiu importantes laços de solidariedade com mulheres que, assim como ela, viveram as dificuldades de criar seus filhos sem a presença de um companheiro" (BARRETO, 2019, p. 106). Ademais, ela registra que, a partir de 1888, surgiu um cenário em que mulheres e homens negros egressos do cativeiro circulavam com mais frequência por praças e ambientes públicos das grandes capitais. Em Salvador, que é seu lócus de estudo, esses sujeitos buscavam sobreviver com diversas formas de ganhos, por exemplo, realizando serviços no comércio local ou retirando dos rios e das matas recursos para a subsistência. Já nos grandes sertões da Paraíba, era corriqueiro ver mulheres negras desempenhando atividades como quitandeiras, ou seja, sobrevivendo das vendas de hortaliças. Claudia Miranda e Carla Silva (2019) descrevem a trajetória de uma negra liberta que também desenvolvia essa mesma atividade no sertão nordestino:

Gertrude alcançou o status de quitandeira podendo, assim, garantir seu sustento. A condição de comerciante autônoma permitia uma grande mobilidade para circular pela cidade, o que lhe garantiu amizade com pessoas de todas as classes, livres, escravizadas, pobres e ricos. (MIRANDA; SILVA, 2019, p. 106)

As autoras demonstram, assim, que as mulheres negras eram bem articuladas e perspicazes para penetrar nas tramas das relações micro e macroestruturais do sistema escravista. É fundamental destacar que suas estratégias de resistência estavam presentes em muitos contextos, como no Rio de Janeiro, mencionado anteriormente, e em outras porções do Sudeste do Brasil. Como explica Lorena Telles (2019, p. 54):

Assim, o contexto urbano do Rio de Janeiro, na primeira metade do século, e sua economia monetarizada abriram maiores oportunidades para a negociação da compra da liberdade com seus senhores, o que proporcionou uma importante população de forras na cidade.

No cotidiano pós-promulgação da Lei do Ventre Livre nessa região, isto é, após 1871, as atividades de comércio foram utilizadas não apenas para a venda dos bens da grande elite senhorial da época, mas também como meios para que as mulheres negras guardassem recursos em busca das cartas de alforrias, pois, "a Lei de 1871 oficializou o direito dos escravizados a disporem de bens e conquistarem a alforria pela autocompra mesmo sem anuência senhorial” (TELLES, 2019, p. 58). Assim como em outros estados brasileiros, as mulheres usaram as atividades de quitandeiras para se manter, tendo em vista que as promessas de "liberdade” não eram acompanhadas de garantias sociais e condições de vida favoráveis. 
[O] cotidiano das quitandeiras escravizadas envolvia armar bancas no largo da Sé, ou no mercado da Candelária, na beira da baía da Guanabara, vendendo frutas, aves, ovos, peixes e verduras. Outras venciam a cidade a pé, apregoando flores, doces, comida pronta, tecidos, artigos de armarinho, ervas de poderes mágicos e abortivos e uma infinidade de outros produtos vendidos a varejo, carregados em cestos, bandejas de madeira ou caixas que levavam à cabeça. Em pontos fixos ou em trânsito, as escravas vendedoras disputaram com outras cativas e com as forras os frutos de seu comércio. Valores diários eram estipulados pelos senhores, sendo que elas acumulavam os excedentes para si, gerando poupanças. (TELLES, 2019, p. 53)

Nos estados do Grão-Pará e Maranhão, conforme sugerem Antônia Mota e Maísa Cunha (2017), mulheres e homens negros também exerceram atividades ligadas ao comércio, bem como um importante papel na exportação de novos produtos. Um elemento primordial observado - e que ratifica novamente as duras realidades - no contexto pós-abolição se liga ao fato de os escravizados libertos serem excluídos de toda e qualquer forma de atividade laboral oficializada. Sobreviviam de atividades no setor agrícola, mesmo sem terras e sem capital: "moradores pobres livres e libertos, em especial os das vilas de Rosário e Itapecuru Mirim, que, provavelmente sem terras e sem capital, sobreviviam à margem dos negócios agrícolas e mercantis" (MOTA; CUNHA, 2017, p. 8).

A literatura levantada evidencia, portanto, a presença de mulheres negras africanas escravizadas em todas as regiões brasileiras, porém, devido à política econômica da época, com maior concentração no Norte e Nordeste. Essa é uma informação histórica importante para que se compreenda o fato de o Norte do país possuir o maior número de famílias com baixa renda chefiadas por mulheres e negras, bem como o maior número de comunidades quilombolas.

Como foi possível refletir, ao longo de séculos, o ativismo dessas mulheres concentra lutas e resistências por sobrevivência de seus corpos, de seus filhos e de seus territórios. Entretanto, é importante ressaltar que, conquanto sem o devido reconhecimento por parte do feminismo classista e, muito menos, do liberal, ambos construídos por mulheres brancas, como problematiza bell hooks (2020), o feminismo negro apresenta-se como um potente projeto de emancipação e superação das desigualdades estruturais na América Latina.

\section{Considerações finais}

Com base nos pressupostos metodológicos da RSL, o tema em questão foi examinado em produções dos últimos cinco anos, com o objetivo de verificar a agência das mulheres escravizadas na diáspora africana no chamado "novo mundo". 
Os estudos levantados desconstroem as narrativas hegemônicas de passividade da mulher e, particularmente, da mulher negra, que sofreu a desumanização dos seus corpos. Apresentam dados importantes sobre a luta pelo empoderamento das afro-latino-americanas, tanto individualmente como em grupo. Com isso, a partir da influência feminina negra para desestabilizar as estruturas opressoras, eles contribuem com novas bases conceituais para o entendimento dos sistemas de dominação e suas estruturas de poder.

O conjunto da literatura analisada, como citado nas palavras iniciais deste texto, insere-se na perspectiva hermenêutica da dialética entre opressão e ativismo, a fim de mostrar que as mulheres negras escravizadas lutaram nos seus grupos pela sobrevivência. Sobreviver, no contexto da colonização das Américas, exigiu delas táticas de enfrentamento contra opressões interseccionais de raça, gênero, sexualidade e nação, como indica Patrícia Collins (2019). Essas ações de combate ao projeto colonial reverberaram nas lutas dos feminismos negros no mundo. Seguem, hoje, em muitas frentes, como é o caso das mulheres que lideram a defesa dos territórios tradicionalmente ocupados.

No Brasil, há uma forte presença de mulheres quilombolas, de terreiros, ribeirinhas assentadas, extrativistas, coletoras, marisqueiras, quebradeiras de coco babaçu, entre outras, que cotidianamente sofrem as ameaças dos deslocamentos forçados, frutos das alianças escusas entre Estado e capital. As mulheres negras também estão nas cidades lutando pela sobrevivência, por moradia, condições dignas de habitação e de trabalho, pela efetivação de políticas de saúde, educação e assistência social. Permanecem atuantes em meio ao racismo, classismo, machismo e sexismo, os quais persistem como produtos da colonialidade.

Na América Latina, contudo, o feminismo hegemônico, herdeiro do feminismo europeu, levado a cabo por mulheres brancas, escolarizadas e de classe média, invisibiliza a luta das mulheres negras. Como afirma bell hooks (2020, p. 72), “[m] ulheres privilegiadas, muitas das quais se denominam feministas, simplesmente se afastaram da ‘feminização da pobreza”. A “feminização da pobreza” se constitui de mulheres que se defrontam cotidianamente com o descaso do governo às mães chefas de família, como nos casos de desmonte do sistema de assistência social e de falta de políticas que garantam os direitos básicos. Desse modo, o racismo afirma-se como estrutural das desigualdades, pois esse sistema cria, segundo a autora, "uma nova classe, inferior, de mulheres e crianças, para serem abusadas e exploradas, pela estrutura de dominação existente” (HOOKS, 2020, p. 73).

No contexto latino-americano e, particularmente, brasileiro, Lélia Gonzales (2018), segundo um pensamento antidiaspórico, anticolonial, pan-africanista, 
problematiza e desconstrói o mito da democracia racial do pós-abolição. Para isso, argumenta que, na formação da favelização das cidades e da institucionalização de territorialidades das desigualdades, a resistência das mulheres negras foi redimensionada para o enfrentamento de múltiplas formas de violências desencadeadas pelo racismo estrutural, institucional e comportamental. Nesse sentido, o mito da democracia racial é a face do colonizador interno do pós-abolição, o que muito explica o fato de o Atlas da Violência de 2019 (IPEA, 2019) apontar as mulheres negras como as maiores vítimas do feminicídio no Brasil.

As reflexões deixadas por Lélia Gonzales acerca do mito da democracia racial no Brasil, problematizado da perspectiva interseccional de gênero, raça e classe, são um convite à análise das estruturas dominantes da sociedade, que se encontram, atualmente, sob o autoritarismo das forças conservadoras que governam o Estado brasileiro. Os direitos básicos constitucionais estão ameaçados pelo acirramento do racismo, o qual aprofunda as desigualdades de classe e de gênero. Agrava-se, igualmente, a violência contra mulheres, territórios tradicionais, povos indígenas e do campo.

A partir da discussão aqui realizada, espera-se ter lançado luzes sobre as experiências de mulheres negras que são atravessadas por opressões que estão na base das relações sociais, sustentadas pelo capitalismo, pelo heteropatriarcado, pela supremacia branca, frutos da estrutura de colonização europeia. Ademais, almeja-se ter contribuído à reivindicação do reconhecimento do pensamento intelectual das "forasteiras de dentro" para o questionamento do lugar neutro que a ciência branca, eurocêntrica e masculina se coloca na produção do conhecimento. Por fim, deseja-se ter colaborado com o campo epistemológico do pensamento sociológico contemporâneo que problematiza o par colonialidade/modernidade, bem como com os feminismos que questionam a história da colonização e da pós-colonização na América Latina da perspectiva da/os colonizada/os, de forma a compreender suas múltiplas intersecções e a empreender políticas de enfrentamento e emancipação.

\section{Referências}

ARIZA, M. B. Mães libertas, filhos escravos: desafios femininos nas últimas décadas da escravidão em São Paulo. Rev. Bras. Hist., São Paulo, v. 38, n. 79, p. 151-171, 2018.

BARRETO, V. Q. Da escravidão à liberdade: a história de Maria da Conceição, roubada e escravizada (Nazaré, 1830-1876). Estud. Hist., Rio de Janeiro, v. 32, n. 66, p. 101-122, 2019.

CABRERA, O. Gênero, sexo e raça e a formação de subjetividades femininas em Cuba, século XIX. Estud. Fem., Florianópolis, v. 25, n. 1, p. 117-145, 2017. 
CARVALHO, F. P. Negras e negros na justiça de Buenos Aires: conflitos e solidariedade em tempos de escravidão. C.1750-C1820. 2019. Tese (Doutorado em História) - Programa de Pós-Graduação em História, Universidade Federal Fluminense, Niterói, 2019.

COLLINS, P. H. Aprendendo com a outsider within: a significação sociológica do pensamento feminista negro. Sociedade e Estado, Rio de Janeiro, v. 31, n. 1, p. 99-127, 2016.

COLLINS, P. H. Pensamento feminista negro: conhecimento, consciência e a política do empoderamento. São Paulo: Boitempo, 2019.

CUNHA, M. F. Casamentos mistos: entre a escravidão e a liberdade. Rev. Bras. Estud. Popul., São Paulo, v. 34, n. 2, p. 223-242, 2017.

ESTEVE, B. J. El comercio de esclavos a Cuba (1790-1840): una proporción femenina. Anu. Colomb. Hist. Soc. Cult., Bogotá, v. 41, n. 2, p.107-130, 2014.

GONZALES, L. Lélia Gonzalez: primavera para as rosas negras. São Paulo: CPA Editora, 2018.

HOOKS, b. O feminismo é para todo mundo: políticas arrebatadoras. Rio de Janeiro: Rosas dos Tempos, 2020.

IPEA. Instituto de Pesquisa Econômica Aplicada. Atlas da Violência 2019. IPEA, Brasília, 05 jun. 2019. Disponível em: https://www.ipea.gov.br/portal/index.php?option=com_content\&view=article\&id=34784. Acesso em: 15 nov. 2020.

KÜHN, F. O contrabando de escravos na Colônia do Sacramento (1722-1777). Tempo, Niterói, v. 23, n. 3, p. 443-463, 2017.

LIMA, I. S. A voz e a cruz de Rita: africanas e comunicação na ordem escravista. Rev. Bras. Hist., São Paulo, v. 38, n. 79, p. 41-63, 2018.

MELO, P. B. Matronas afropacíficas: fluxos, territórios e violências: gênero, etnia e raça na Colômbia e no Equador. 2015. Tese (Doutorado em Antropologia Social) - Programa de Pós-Graduação em Antropologia Social, Universidade de Brasília, Brasília, 2015.

MIRANDA, C.; SILVA, C. "Ponha os olhos em mim”: sobre direitos humanos e memórias de luta das mulheres escravizadas no Brasil. Plurais, Salvador, v. 4, n. 2, p. 92-115, 2019.

MOTA, A. S.; CUNHA, M. F. No âmago da africanização: pessoas negras e de cor nos mapas populacionais do Maranhão colonial (1798-1821). Rev. Bras. Estud. Popul., São Paulo, v. 34, n. 3, p. 465-484, 2017.

SANTOS, S. B. Ação política e pensamento das mulheres negras nas Américas: uma perspectiva sobre a diáspora africana. Espaço e Cultura, Rio de Janeiro, n. 38, p. 65-84, 2015.

TELLES, L. F. S. Teresa Benguela e Felipa Crioula estavam grávidas: maternidade e escravidão no Rio de Janeiro (século XIX). 2018. Tese (Doutorado em História Social) - Faculdade de Filosofia, Letras e Ciências Humanas, Universidade de São Paulo, São Paulo, 2018. 


\section{Maria Amoras}

Antropóloga. Doutora em Ciências Sociais - Antropologia. Professora Adjunta da Faculdade de Serviço social e do Programa de Pós-Graduação em Serviço Social da Universidade Federal do Pará.

Email: samoras@ufpa.br

ORCID: 0000-0003-0785-4490

Contribuição de autoria: Conceituação; Investigação/Pesquisa; Administração do Projeto; Análise Formal; Supervisão/orientação; Validação; Escrita - Primeira Redação.

\section{Solange Maria Gayoso da Costa}

Assistente Social. Doutora em Ciências Socioambientais. Professora Associada I da Faculdade de Serviço Social e do Programa de Pós-Graduação em Serviço Social da Universidade Federal do Pará.

Email: solgayoso@ufpa.br

ORCID: 0000-0002-5542-3663

Contribuição de autoria: Conceituação; Investigação/Pesquisa; Metodologia; Supervisão/orientação; Visualização; Escrita - Revisão e Edição.

\section{Luana Mesquita de Araújo}

Graduada em Licenciatura Plena em Letras - Língua Portuguesa pela Universidade do Estado do Pará. Graduanda do curso de Serviço Social da Universidade Federal do Pará.

Email: luanamesquitao@gmail.com

ORCID: 0000-0002-3631-7873

Contribuição de autoria: Conceituação; Investigação/Pesquisa; Escrita - Revisão e Edição. 
Submissão: 24 de novembro de 2020.

Aprovação: 23 de julho de 2021.

Como citar: AMORAS, M.; COSTA, S. M. G.; ARAÚJO, L. M. O ativismo das mulheres negras escravizadas no Brasil colonial e pós-colonial, no contexto da América Latina. Revista brasileira de estudos urbanos e regionais. Dossiê Território, Gênero e Interseccionalidades. v. 23, E202128, 2021. DOI 10.22296/2317-1529.rbeur.202128

Artigo licenciado sob Licença Creative Commons CC BY 4.0.

https://creativecommons.org/licenses/by/4.o/deed.pt_BR 